\title{
AC 2011-2009: DESIGN OF A SENIOR LABORATORY SEQUENCE TO GUIDE STUDENTS IN MULTIPLE ACADEMIC PROGRAMS TOWARDS WORKFORCE PREPAREDNESS
}

\section{Philip H. Harding, Oregon State University}

Dr. Harding has served since 2007 as the Linus Pauling Distinguished Engineer at Oregon State University School of Chemical, Biological, and Environmental Engineering. He has worked in the oil, pulp and paper, and microelectronic industries with a history of responsibilities including process engineering, research and development, product reliability, and worldwide manufacturing and research strategy. He holds 14 patents, with another 9 pending. Most recently, he worked for Hewlett-Packard Company in the role of Master Technologist.

\section{Milo Koretsky, Oregon State University}

Milo Koretsky is an Associate Professor of Chemical Engineering at Oregon State University. He currently has research activity in areas related to thin film materials processing and engineering education. $\mathrm{He}$ is interested in integrating technology into effective educational practices and in promoting the use of higher level cognitive skills in engineering problem solving. Dr. Koretsky is a six-time Intel Faculty Fellow and has won awards for his work in engineering education at the university and national levels. 


\title{
Design of a Senior Laboratory Sequence to Guide Students in Multiple Academic Programs Towards Workforce Preparedness
}

\begin{abstract}
This paper describes the integration of upper division experiential laboratory and project courses in the chemical engineering, biological engineering, and environmental engineering programs at Oregon State University. Student enrollment has doubled during this 5 year process. The yearlong integrated curriculum is built around a theme of "college to career" transition and targets a wide array of learning objectives. This paper focuses on three: experimental methodology, communication, and project management. It is demonstrated that the dramatic changes have been implemented while successfully maintaining positive student perceptions as measured with student course evaluations.
\end{abstract}

\section{Introduction}

The senior laboratory plays a vital role in preparing students for engineering practice. To this end, they can include a wide array of learning objectives which often vary by discipline or program. ${ }^{1,2}$ The learning objectives are typically aligned to specific ABET guidelines that focus on the practice of engineering, including requirements for communication, teamwork, creativity, the synthesis of core engineering concepts applied to an open-ended project, incorporation of economic considerations, and inclusion of relevant health, safety, and ethical issues. ${ }^{3}$ Industrial needs have also shaped the development of laboratory courses in a variety of ways, from reporting a perceived lack of hands-on-experience in recently graduated engineers to providing mentorship and projects for capstone course. ${ }^{4}$ A recent trend in laboratory instruction includes the introduction of alternative modes for the laboratory, including virtual and remote laboratories. ${ }^{5}$ These alternative modes have been shown to provide an opportunity for a wider array of learning objectives to be addressed. ${ }^{6}$ A survey of capstone courses in 360 engineering departments across the country identified teamwork and project managements as the top lecture topics. $^{7}$

Feisel and Rosa ${ }^{1}$ state that "while much attention has been paid to curriculum and teaching methods, relatively little has been written about laboratory instruction.” To make matters worse, they assert, "In most papers about laboratories, no course objectives or outcomes are listed."

While the majority of papers in the literature do indeed focus on equipment design, reports have identified how project management ${ }^{8,9}$ and writing ${ }^{10}$ skills are developed.

This paper describes the integration of upper division experiential laboratory and project courses in the chemical engineering, biological engineering, and environmental engineering programs at Oregon State University. We address a subset of the learning objectives targeted in the integration of the senior laboratory sequence, specifically that "At the end of these courses, 
students should be able to: (a) design and conduct experiments, as well as to analyze and interpret data; (b) communicate effectively; and (c) implement formal practices of project planning and management.

\section{Curricular Context and Design}

In 2002, the biological engineering program at Oregon State University joined the Department of Chemical Engineering (CHE) at Oregon State University. Five years later the environmental engineering program was incorporated, and the department renamed the School of Chemical, Biological, and Environmental Engineering (CBEE). Since this time, CBEE has worked toward a common curricula for these three "process engineering” degree programs where appropriate. Figure 1 summarizes the student distribution from the past 3 years, showing also the "academic options" pursued by the majority of chemical engineering students.
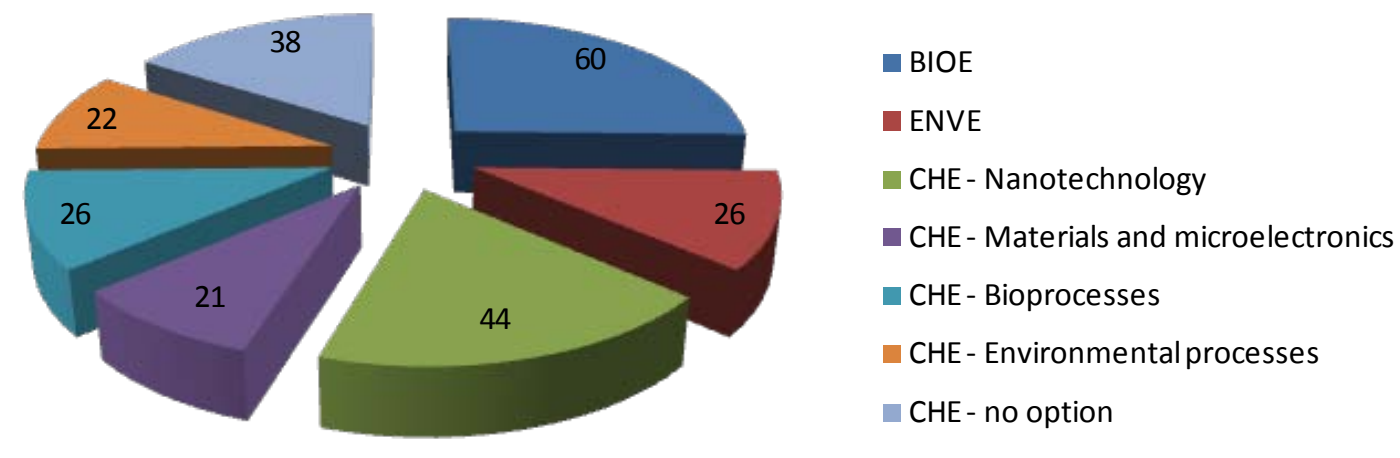

Figure 1: Distribution of student academic programs over the past 3 academic years. Most chemical engineering students declare academic "options" that correspond to specific coursework. CHE=chemical engineering, $\mathrm{BIOE}=$ bioprocess engineering, $\mathrm{ENVE}=$ environmental process engineering.

This paper addresses one component of this curricular integration, the senior laboratory sequence. This integration been enabled by an endowed teaching position, the Linus Pauling Engineer chair, ${ }^{11}$ whose position description includes providing instruction in the senior laboratory courses, establishing stronger ties with industry, and developing student communication, project management, and leadership skills. This integration in the senior laboratory course sequence is shown schematically in Figure 2. CHE 414 and 415 were historically taught in winter and spring. A common course, CBEE 414 has been developed for fall term, integrating the three programs. Separate and distinct unit operation laboratory curriculum were developed for the two new programs in the winter (BIOE 415 and ENVE 415), and a new senior project course developed for spring (CBEE 416). Each course is 3 credits and meets in a single lecture section 2 hours per week. Convolving the three class schedules required a reduction in scheduled weekly student laboratory time from 6 to 3 hours. Senior projects are generated from faculty volunteers and also from partnerships with local industry. A current goal 
is to have roughly equal number of projects from faculty and industry. Whenever possible, projects that include multiple disciplines are developed.

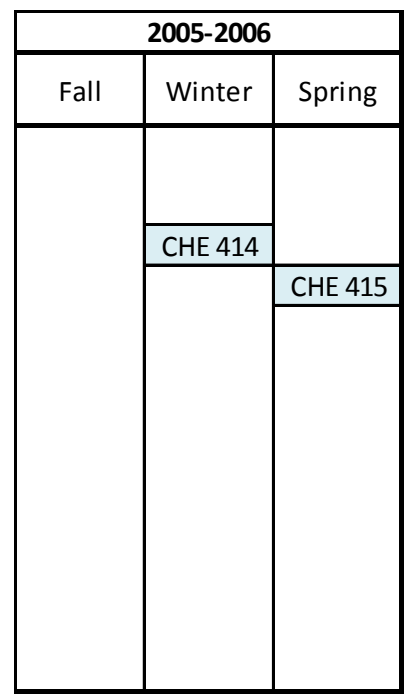
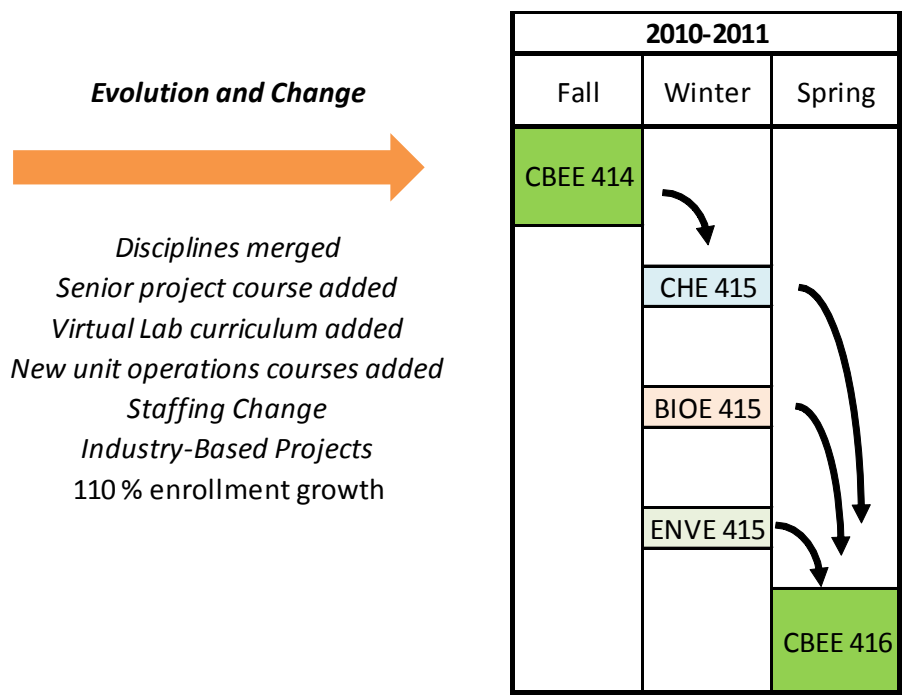

Figure 2: Evolution of the CBEE senior laboratory sequence. The sequence is now interdisciplinary in nature and culminates in a senior project.

The senior laboratory sequence is framed as the final steps and significant contributor to graduate workforce preparedness. Consequently, the student learning objectives and outcomes are broad and include many so-called "soft skills". These soft skills include written and verbal communication, teamwork, and project management. The transition that students experience between their academic and professional careers is shown thematically in Figure 3. Students are reminded of this "college to career" transition theme regularly throughout the year as new topics are introduced and they wrestle with increasing open-endedness and ambiguity. Workforce preparation amounts to creating proactive individuals with higher order cognitive, professional and team skills.

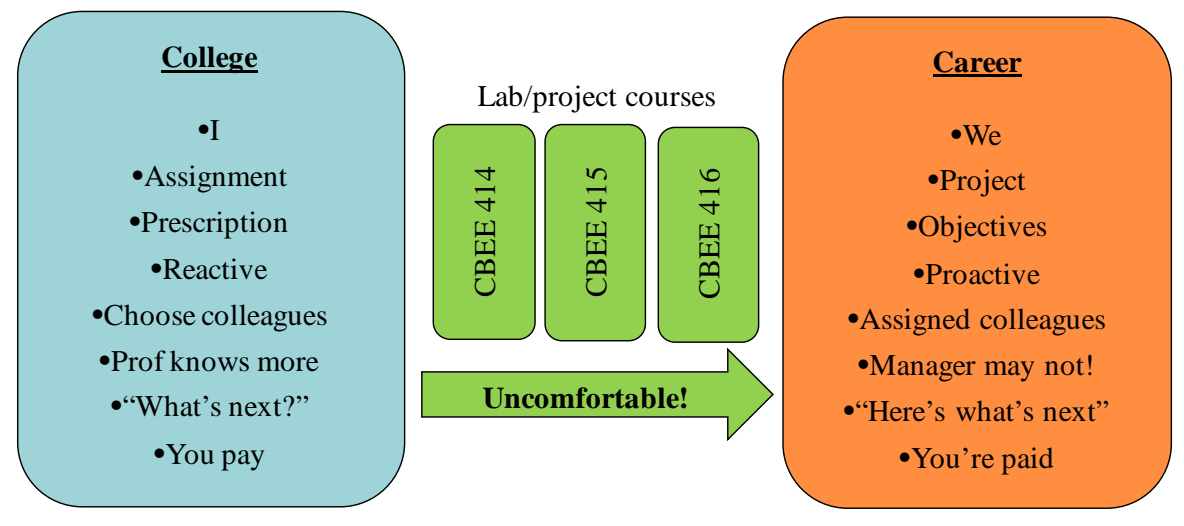

Figure 3: Schematic describing thematic transitions as a student leaves college and joins the workforce. The structure of this schematic is extended in Figure 4 to represent lecture and laboratory content throughout the course sequence. 
Figure 3 is expanded in Figure 4 to convey the current curriculum summary. The content of CBEE 414 is essentially identical for all three disciplines. It is a writing-intensive course for our students. The Linus Pauling Engineer serves as the lead instructor and two CBEE faculty members serve as "subject matter experts”. CHE/BIOE/ENVE 415 has a shared lecture component and discipline-specific laboratories, and CBEE 416 is the senior project course, which is devoted to a single, original project. In both these courses, the Linus Pauling Engineer serves as the lead instructor and several CBEE faculty members provide projects and serve as mentors for project teams. Written communication is emphasized early in the year, then oral communication and project management fundamentals. Laboratory activities generally grow from prescriptive to open-ended, general to discipline-specific, and limited scope to larger scope.

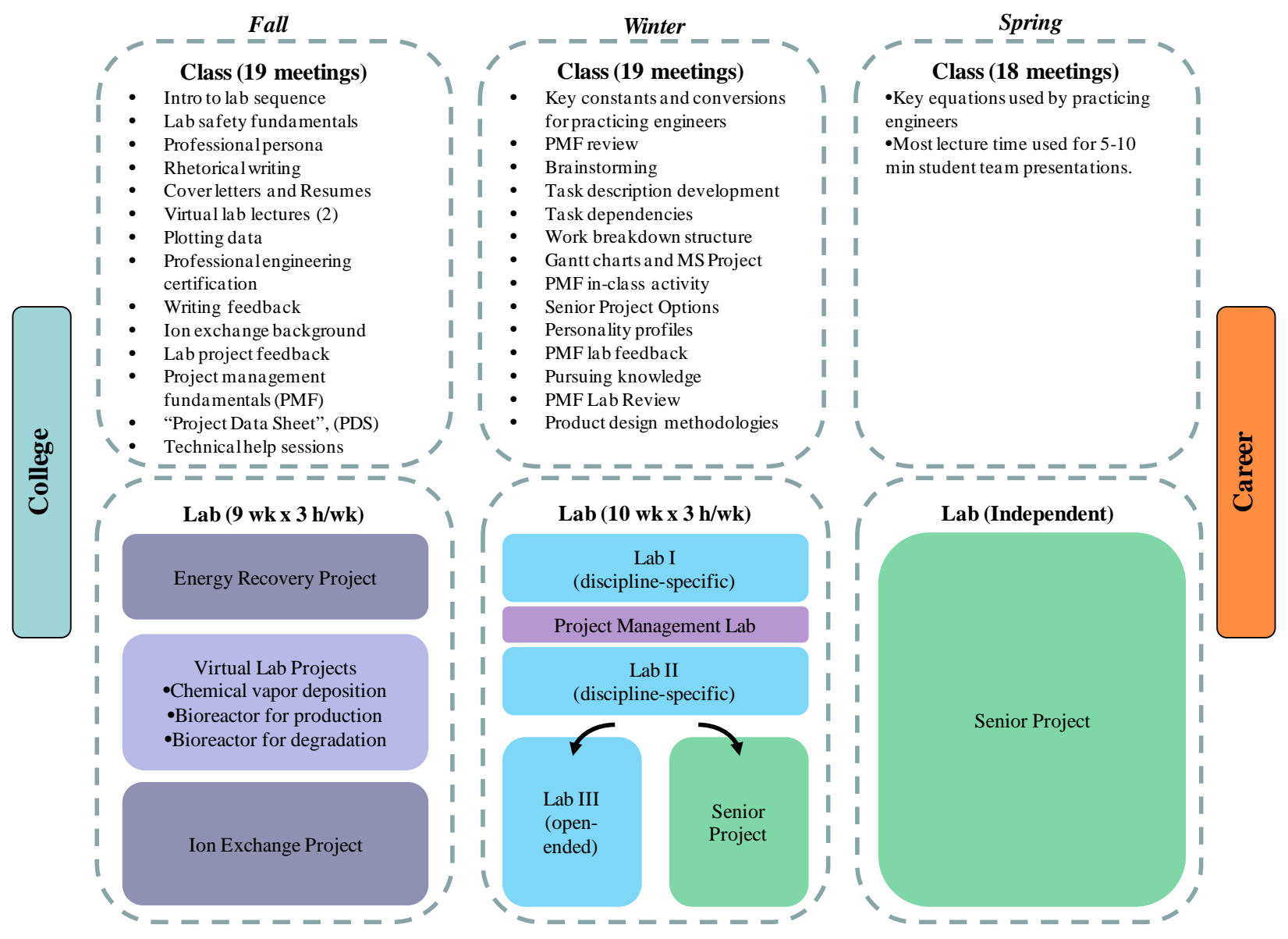

Figure 4: Lecture and laboratory curriculum of the CBEE senior laboratory sequence for the 2009-2010 academic year. Fall quarter is a Writing Intensive Course with more straight-forward laboratory projects. Winter quarter is the typical "unit operation" laboratory course, and students decide early whether to embark on a 14-week senior project through the spring.

Significant effort goes into creating contact between students and practicing professionals. In the fall, a unit in professional engineering certification is presented and features guest panel speakers from different industries. In the winter, units in project management fundamentals, performance 
evaluation for engineers, and product design feature practicing engineers from various industries. In the spring, many senior projects involve practicing engineers.

The following sections describe curriculum designed to enable student growth on experimental methodology (haptic and cognitive), communication (written and verbal), and project management skill areas.

\section{Experimental Methodology Development}

Experiments transition from more prescriptive to more open-ended and ambiguous over the year. Early physical laboratory experiences are relatively prescriptive and have specific equipment operating protocol and guidance provided. Virtual laboratories are incorporated to introduce the iterative experimental design process and ambiguity. Unit operations projects combine ambiguity with increase in equipment complexity. Senior projects then provide opportunity for application of these skills to a more extensive project.

\section{Fall Quarter}

Fall is focused on laboratory protocol, safety, and experimental design. The laboratory component consists of a weekly 3-hr meeting time. Students self-select teams of 3 which remain for the duration of the course. There are 3 laboratory projects over the course of the quarter which are common to all 3 disciplines: Energy Recovery, Virtual Laboratory (no equipment required), and Ion Exchange, as shown in Figure 4. No significant preparation is expected from students prior to laboratory.

The Energy Recovery project is crafted to have students investigate energy recovery from a waste steam source to heat potable water. Equipment consists of a conventional kitchen pressure cooker to create a low-pressure "waste” steam source ( $<5$ psig) that feeds steam to a bench-scale pipe-in-pipe heat exchanger. Simple plumbing fittings are used to supply municipal water to the water-side tube. Stream inlet and outlet temperatures are measured using thermocouples and digital thermometers. The necessity of calibration curves and understanding sensor data (e.g. thermocouple type J vs. K) is emphasized. There are 6 identical laboratory stations with each station having equipment and dedicated bench space.

Virtual laboratories provide opportunity to practice iterative experimental design and introduce open-endedness, ambiguity, and realistic considerations such as operating and measurement costs. They allow instructors to put physical laboratory procedures, e.g. rotameter calibration, "on hold" to allow the student to engage in other elements of the experimental design process. ${ }^{12}$ A schematic comparison of the physical and virtual laboratories is shown in Figure 5. 


\section{Physical Unit Operation Lab}

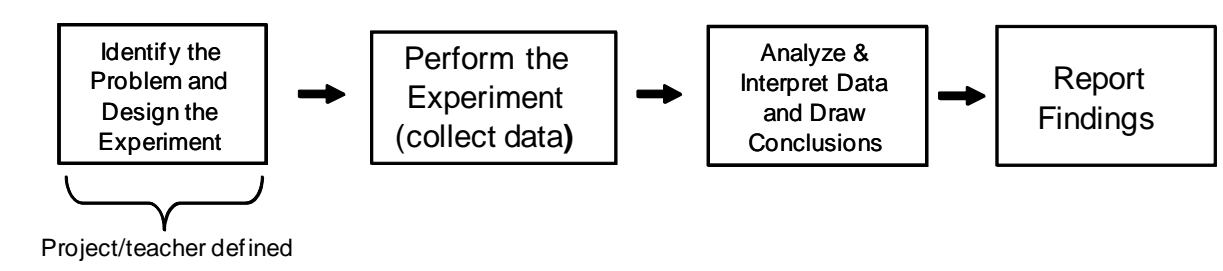

\section{Virtual Lab}

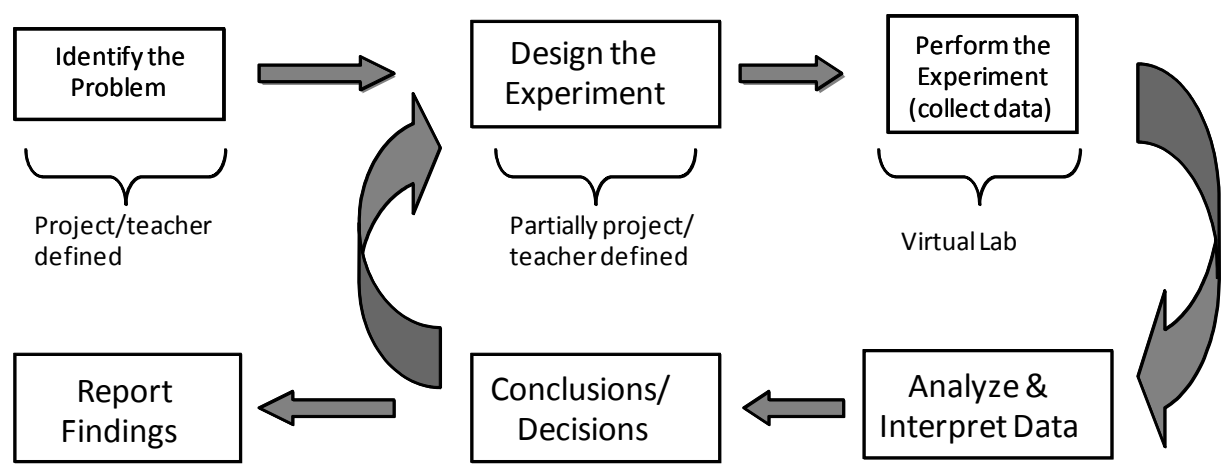

Figure 5: Schematic comparing discovery approach of a virtual laboratory to that of a conventional physical laboratory. The virtual laboratory is not burdened by the "real world" issues of making up chemicals, broken tubing, etc., and hence allows more learning cycles.

Students choose between two virtual laboratory projects: chemical vapor deposition or a bioreactor, with the latter having options for pharmaceutical production or waste degradation. ${ }^{13,14}$ Analysis of anonymous post-laboratory assessment surveys indicates that students perceive the physical laboratories to be less "ambiguous" after the virtual laboratory project. ${ }^{15}$

The Ion Exchange project is crafted to have students characterize an ion exchange resin and design a process to treat a waste stream. Equipment consists of a bench-scale ion exchange column packed with ion exchange resin. Students deliver a $\mathrm{Ca}^{2+}$ solution through the resin and measure concentration using simple home aquarium kits that feature a dropwise titration and color indicator. The data for both adsorption and resin regeneration are analyzed using simple integrations. The importance of confidence intervals for both property determination and process design parameters is emphasized. There are 6 identical laboratory stations with each station having equipment and dedicated bench space.

\section{Winter Quarter}

Winter focuses more on laboratory preparation, experimental design, and increased equipment complexity. The laboratory component consists of a weekly 3-hr meeting time. Students are assigned to teams of 3 based on distribution of academic performance in CBEE 414 (one each low, medium, and high performance). These teams are in place for the first half of the course. 
Safety practices are more formally introduced with material safety data sheets, hazard identification, and personal protective equipment (PPE) requirements for each laboratory. Laboratories are discipline-specific. Significant preparation is expected from students prior to laboratory periods. At mid-quarter, approximately two thirds of the students commit to undertake a senior project and to enroll in CBEE 416.

“Unit operation” physical laboratories are the emphasis of this course. Historical chemical engineering laboratories such as distillation and liquid-liquid extraction have been retired and replaced with smaller scale experiments in consideration of facilities limitations. Laboratory projects for the BIOE 415 and ENVE 415 courses have been developed by supporting faculty. The various laboratories are summarized in Table 1.

Table 1. Overview of unit operation experiments used in Winter 2011. Future improvements will include both scale-up of equipment and transition to processes most relevant to graduates.

\section{Chemical Engineering}

- Continuous stirred tank reactor

- Plug flow reactor

- Gas absorption column

- Coagulation and settling

- Plasma etching

- Cook stove comparison

\section{Bioprocess Engineering}

- Bioreactor for production

- Micro-filtration

- Ultra-filtration

\section{Environmental Engineering}

- Coagulation and settling

- Stream aeration

- Wastewater filtration

The emphasis on laboratory preparation is communicated early by investing the first laboratory period in an equipment walkthrough designed to familiarize students with equipment for all three disciplines. Student teams "tour" the equipment together and individually draw detailed process flow diagrams and list both independent and dependent variables (description, nomenclature, and units) for 8 of the unit operations listed in Table 1.

Preparation for ensuing laboratories is done via individual "Pre-Laboratory" assignments that sum to 30 percent of student grade and consists of the following:

- MSDS and PPE

- Project and process written description

- Relevant curriculum

- Background research
- Process flow diagram

- Independent variables (description, nomenclature, units, expected values)

- Dependent variables (description, nomenclature, units, expected values)
- Equations

- Plotting techniques

- Sample calculations

- $1^{\text {st }}$ draft of experimental plan 
period working with a particular unit operation project. Specifically, they submit an abstract draft, Background section, Materials and Methods section, and initial results. This is designed to distribute their work and thereby allow more time for reflection on results versus "writing the report”. These laboratory preparation efforts are designed to offset the significant loss of laboratory time described above.

The last 4 weeks of the quarter are spent engaging an open-ended project. Those students enrolling in CBEE 416 will begin work on their senior projects. Their quarter culminates in a proposal to justify their enrollment for spring quarter. Those not enrolling in CBEE 416 form new teams and work directly with the instructor to create a project of mutual interest. This is often one of the unit operation laboratories with a "twist", developing equipment and protocol to benefit students for the following year, and occasionally a unique project borne of student innovation.

\section{Spring Quarter}

Senior project teams formed mid-winter persist through the spring. Teams consist of 2 to 4 students. These projects feature a tremendous diversity of experimental situations. Projects are conducted in faculty research laboratories, in designated senior laboratory space, and in external laboratories (e.g. local companies, etc.). Projects usually require innovation, device design and construction. There is no scheduled laboratory component; Students manage their own time.

Senior project topics from 2010 are listed in Table 2. Seven of these were in partnership with local industry and several of them were sponsored financially. It is expected that each project have a hands-on component, so the AICHE Student Contest Problem is not well-suited for this. Student course fees allow for each team to have a small budget.

Table 2. Senior project topics from spring 2010. Project documents can be accessed at the web site of the lead author (http://cbee.oregonstate.edu/people/faculty/harding.html).

- Organic-Inorganic Hybrid Solar Cells

- $\quad$ Process Development for Microchannel Devices

- Microchannel Heat Exchange Array Architectures*

- Wireless Based Condition Based Monitoring system*

- Dispense Effects Using Thermal Inkjet for Pharmaceuticals*

- Underseat Bicycle Hydration System*

- Ion Exchange for Cellulosic Ethanol*

- HPLC for Continuous-Flow Production of Nanomaterials

- Mass Spectrometer Characterization of Photovoltaics

- Cell Membrane Permeability
- Development of a Nanospring Microreactor Sensor

- Biomass Production of the bacteria Oenococcus oeni $^{*}$

- Wastewater Reclamation Plant Digester Gas Usage*

- Chemical Vapor Deposition of Carbon Nanoforests

- Surfactant Stabilization of a Human Recombinant Factor VIII

- $\quad$ Nisin Adsorption to Polyethylene Oxide Layers

- Hydrogel Composites for Spinal Disk Replacement

- Development of Microchannel Reactors

- Cell Membrane Permeability Measurement in 3D Tissues

\footnotetext{
*Indicates projects sponsored externally, i.e. industrial/commercial.
} 
The number of senior projects and sponsors over the past three years are shown in Figure 6, along with a forecast for 2011. Faculty researchers provide outstanding support for the program, and the number of industry sponsors has grown. These projects are popular with students and endorsed by the Industrial Advisory Board.

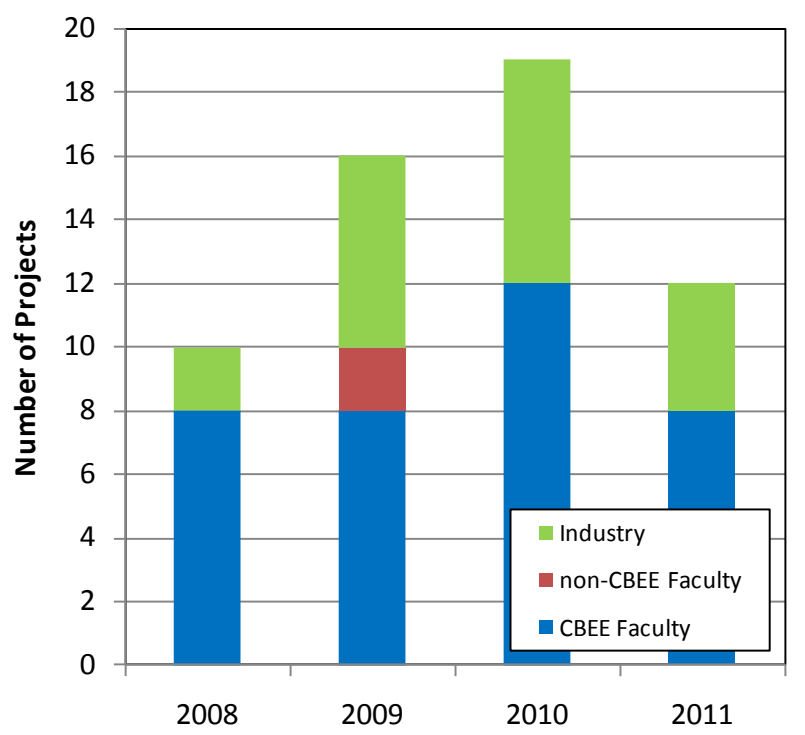

Figure 6: Senior project categories over the past 4 years. The program enjoys great support from faculty and relationships with local industry continue to develop and result in projects. Projects for 2011 are currently underway.

We have learned that:

- even seniors struggle with synthesis of their knowledge and that an early mix of physical and virtual laboratories allows growth in both laboratory and cognitive skills.

- loss in laboratory time can be partially overcome by stressing the importance of laboratory preparation and written communication between laboratory sessions.

- students find a well-managed, longer project very motivating and often include it in their resume.

\section{Communication Skills Development}

Written and oral communication skills are covered in the senior laboratory sequence, with writing being the focus in the fall and the year culminating in multiple oral presentations of different formats.

\section{Fall Quarter}

Oregon State University requires each student to take a Writing Intensive Curriculum (WIC) course $^{16}$ designed to provide students with copious feedback and scaffolded assignments that result in 25-30 pages of refined writing. For our program, that course is CBEE 414. Numerous rewrite opportunities are provided, sometimes required and sometimes optional. A simple 
scheme of "objectives, methods, results" is emphasized for clear and succinct technical communication and applied to resumes, abstracts, and presentations.

In this class, students start with simple assignments to allow initial assessment by the instructor, give the students a low-risk learning opportunity, and enable more rapid feedback. The assignments grow in magnitude, but the instructor's intent is always rapid feedback. Laboratory section enrollments are limited to 18 students to enable immediate review, scoring, and feedback ( $<3$ hour turnaround) provided during laboratory by the lead instructor (Linus Pauling Engineer). The scoring rubric for each assignment changes with time to shift the emphasis from the mechanics of writing to technical content. This shift is shown in Figure 7, which summarizes the scoring rubrics for fall quarter assignments in the WIC course. Early, shorter assignments focus almost exclusively on writing, while the final, significant laboratory report is scored almost completely on technical content.

The WIC instructional guidance of "copious" feedback is taken seriously and early assignment feedback can challenge student morale. Early feedback is given in red ink, but that soon becomes blue, then green in an effort to symbolically acknowledge student effort and progress.

The first oral team presentations of the year are delivered after the virtual laboratory projects are complete. They are typical 10-12 min slide presentations followed by 15 min of questions from students and instructors.

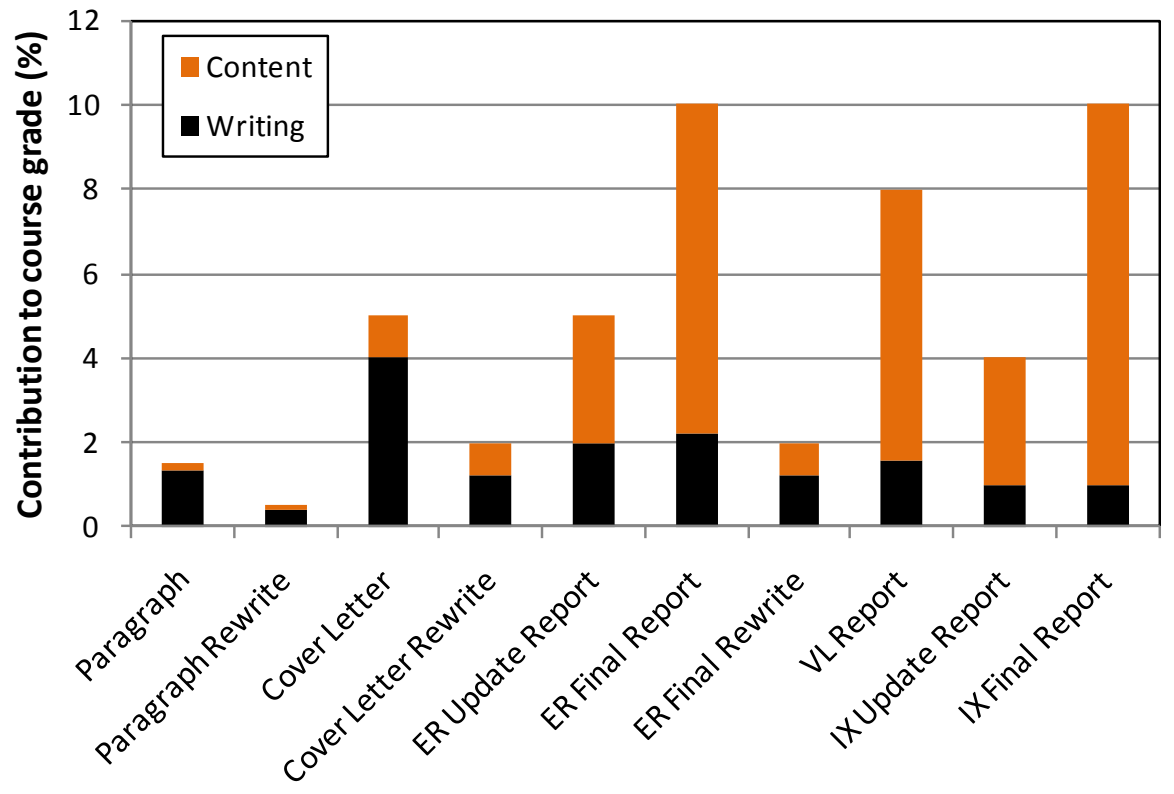

Figure 7: Scaffolding structure for writing skill development over the fall. Early writing assignments are shorter and feedback has emphasis on writing. Final reports have emphasis on content and begin preparing students for project management fundamentals. Rewrites are optional but the majority of students participate. These data are based on rubrics for the Fall 2010. Key: ER = Energy Recovery, VL = Virtual Lab, IX = Ion Exchange. 


\section{Winter Quarter}

The teams in winter feature a balance of student skill level (always at least one academic high performer) and most students have improved their writing in the fall. The result is that most laboratory reports are written very well, and the opportunity to assess and grow writing skills on an individual basis is limited. Some accommodation for this is made by encouraging individual students to write their pre-laboratory assignment (described above) as if it were a report draft. Also helpful is the practice of having teams submit partial reports after their first laboratory session. This provides opportunity for all team members to review and participate (but this is not monitored or assessed). Overall, individual students submit 3 pre-laboratory assignments and teams each submit 3 partial reports and 3 final reports.

Oral presentations of final projects in the quarter ("proposals” for the senior projects) are delivered at the end of the quarter and consist of 15 min slide presentations.

\section{Spring Quarter}

Student teams continue to submit weekly reports on the status of their projects and meet weekly, often with both the instructor and their faculty or industrial sponsor. The status reports are limited to a single page and students are encouraged to emphasize technical content in these reports, i.e. the reader should see dates, names, numbers, dimensions, units, etc. Senior projects

are summarized in comprehensive, final written reports often used for follow-on projects the next year.

The classroom environment is designed to simulate that of an industrial team meeting, where different teams report on their projects objectives and progress. The bulk of the class time in the spring is spent with team slide presentations of 5-10 min in length. The teams have opportunity for formal poster presentations during the May "Engineering Expo Fair” (attended by hundreds) and June in-house “CBEE Expo Lite” (graduation day, attended by friends and family)

We have learned that:

- $\quad$ immediate and copious writing feedback improves student performance and distributes instructor workload.

- it is difficult to provide continuity in individual student writing development in a laboratory-intensive, team environment.

- anecdotal feedback from graduates indicates that strong writing and presentation skills differentiate them in the workplace.

\section{Project Management Skills Development}

Figure 3 portrays that students must move from perspective of being reactive to assignments to being proactive with projects as they enter the workforce. The project management 
fundamentals curriculum is scaffolded to enable that transition and it begins in earnest once the students have established their writing ability. There are 3 components developed over the year: the "project data sheet", "work breakdown", and project scheduling. The project data sheet is a one-page project summary. Work breakdown refers to clearly defining tasks and their durations, owners, and dependencies. Project scheduling is the outcome of the work breakdown in the form of a Gantt chart or other visual aid. The scaffolding structure for their delivery is shown in Figure 8.

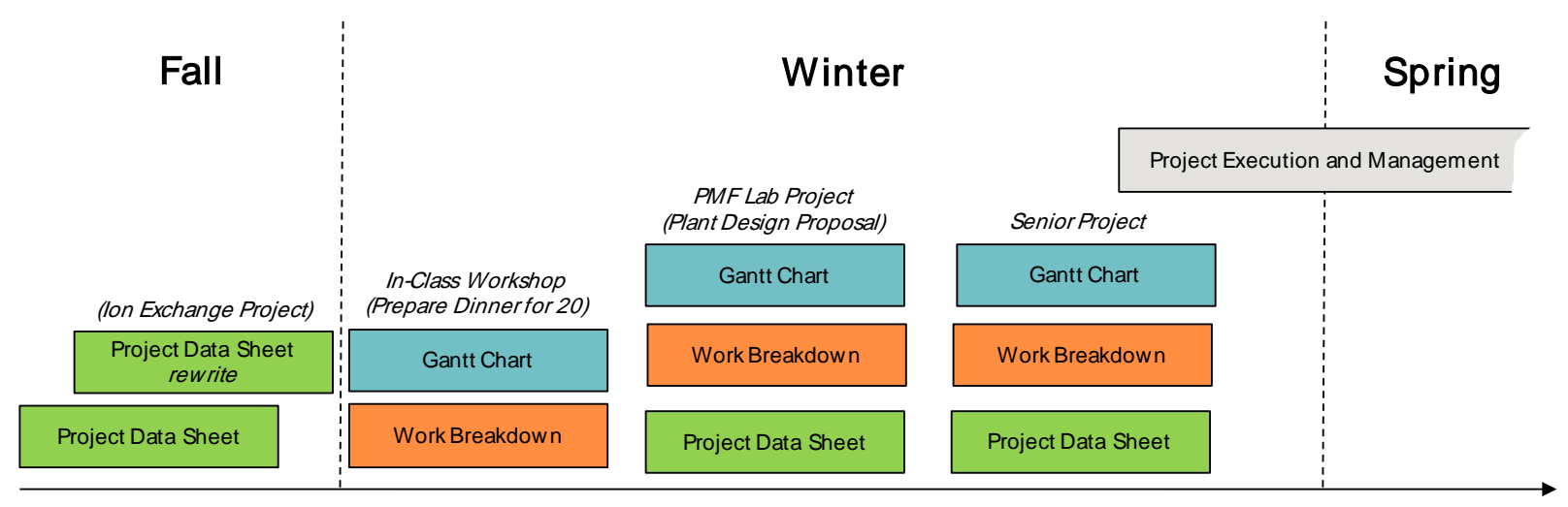

Figure 8: Scaffolding structure for project management skill development over the year long sequence. This is most intense during winter quarter after writing skills can support project planning.

\section{Fall Quarter}

An introduction to project management fundamentals is made in lecture and in the context of the ion exchange laboratory. The instructor clearly differentiates project objectives, often communicated in a short email or memo, from the standard operating procedure (SOP). Students are encouraged to consider and understand the project first, then understand equipment protocol, etc. A student will often bring the SOP to laboratory (the "assignment") but will have little idea of how to structure their work to meet project deliverables. A vehicle for strengthening their understanding of project structure is a one-page project data sheet (PDS) designed to communicate key project management terminology. The project attribute concepts used in the PDS are listed in Table 3.

Table 3. Overview of project management concepts introduced in CBEE 414 and summarized in project data sheets. These concepts are reinforced in CHE/BIOE/ENVE 415 then applied to senior projects.

- Issue

- Objective statement

- Scope

- Schedule

- Resources
- $\quad$ Flexibility matrix

- Deliverables

- Metrics and goals

- Assumptions
- Milestones

- Cost estimates

- $\quad$ Team staffing and availability

- Risks/issues 
The students' first attempt at identifying these project attributes is usually very weak, and (in the spirit of the WIC class) they are provided copious feedback and a rewrite opportunity to understand the project attributes listed in Table 2. The performance on this $2^{\text {nd }}$ attempt is typically excellent.

\section{Winter Quarter}

Figure 4 shows the bulk of CHE/BIOE/ENVE 415 lecture content focused on project management fundamentals. Practicing industrial engineers and managers are invited to class and help lead lecture, activities and feedback. For example, one particular in-class workshop involves completing a work breakdown associated with preparing Thanksgiving dinner for 20 guests: defining tasks (noun/verb, durations, and dependencies or sequencing). The following class period is used to build a Gantt chart from their results.

The skills developed at this point are then applied to a realistic project. In the Project Management Fundamentals (PMF) laboratory, students are assigned to cross-discipline teams of 6 to 8 and given 3 hours to assemble a proposal to design an insulin plant. They are provided guidance as to how to manage their time, and this is shown in Figure 9. The project culminates in a package consisting of a PDS, work breakdown, and Gantt chart. This assignment is scored in part by a practicing engineer and he/she provides feedback in class.

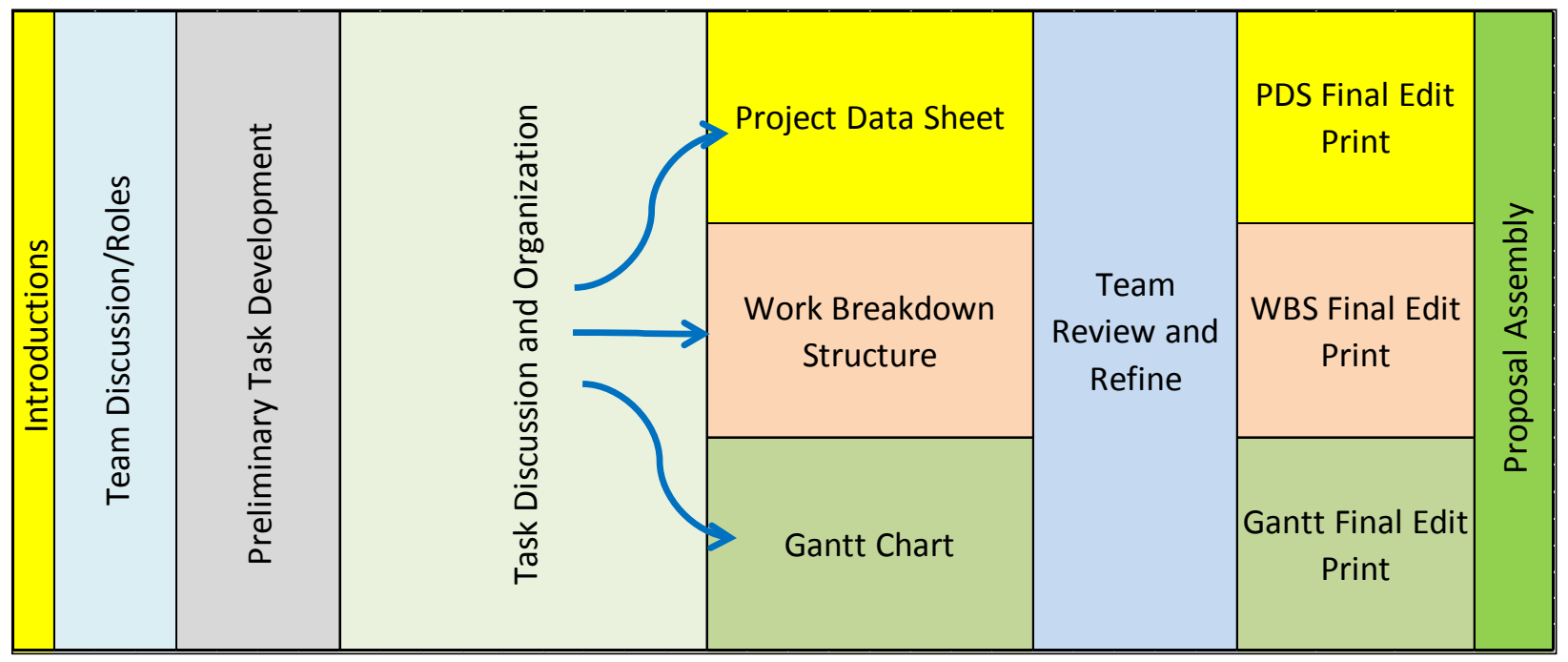

Figure 9: Laboratory period structure for the Project Management Fundamentals laboratory. Students are organized into teams of 6 to 8 . The only preparation required is the ability to use software that allows the building of a Gantt chart. The arrows indicate sub-groups for PDS, work breakdown and Gantt chart formulation.

Project teams are then expected to apply their project management tools to their project launch and are given the freedom to do that. 


\section{Spring Quarter}

Spring is focused on project execution. Teams work on their various sponsored projects and operate with increasing independence. The project management methods taught and coached are meeting preparation and management. Students continue to meet weekly with the instructor and sponsors and use the previously described weekly status report as the meeting agenda.

We have learned that:

- iteration of project management tools is the only successful way to ingrain them in students.

- most student project teams in the past have not used these tools on their own without a requirement from the instructor.

- anecdotal feedback from graduates indicates that project management skills differentiate them in the workplace.

\section{Assessment}

The senior laboratory sequence has served nearly 343 students over the past 5 years. The number of senior projects has doubled and those sponsored by industry has tripled. Moreover, another 50-60 percent enrollment growth is projected for the next two years. The dramatic rate of change has occupied the majority of the instructional staff availability and precluded formal assessment and evaluation. Eventual assessments will investigate both student performance and student perceptions. Student performance assessment in integration courses is difficult when compared to concept courses. Effects on student ability to recall, integrate (synthesize) knowledge, and apply skills learned through previous training are difficult to measure. We plan to develop both pre- and post-intervention assessment of the learning outcomes described here: experimental methodology, communication, and project management. We also plan to more thoroughly characterize the complexity of our operation, e.g. stabilization of writing rubrics as communicated here. The assessment design is ongoing and results will be presented in a future paper.

Student perceptions are more commonly reported, and we report some here. In light of recent program changes, the following research question is asked: Have the changes in course structure, staffing, and enrollment come at the cost of student perceptions of the course? This question is addressed by studying student course evaluations over the past 5 years for all of the courses discussed here. Specifically, student responses to a statement "The course as a whole was...”. Students respond on a Likert scale of 6 with higher scores being more favorable. The average results are shown in Figure 10 and are reported with 90 percent confidence intervals. Bearing in mind the many variables that influence student perception, we can nonetheless conclude that student perceptions of the course as a whole have not been negatively affected. 


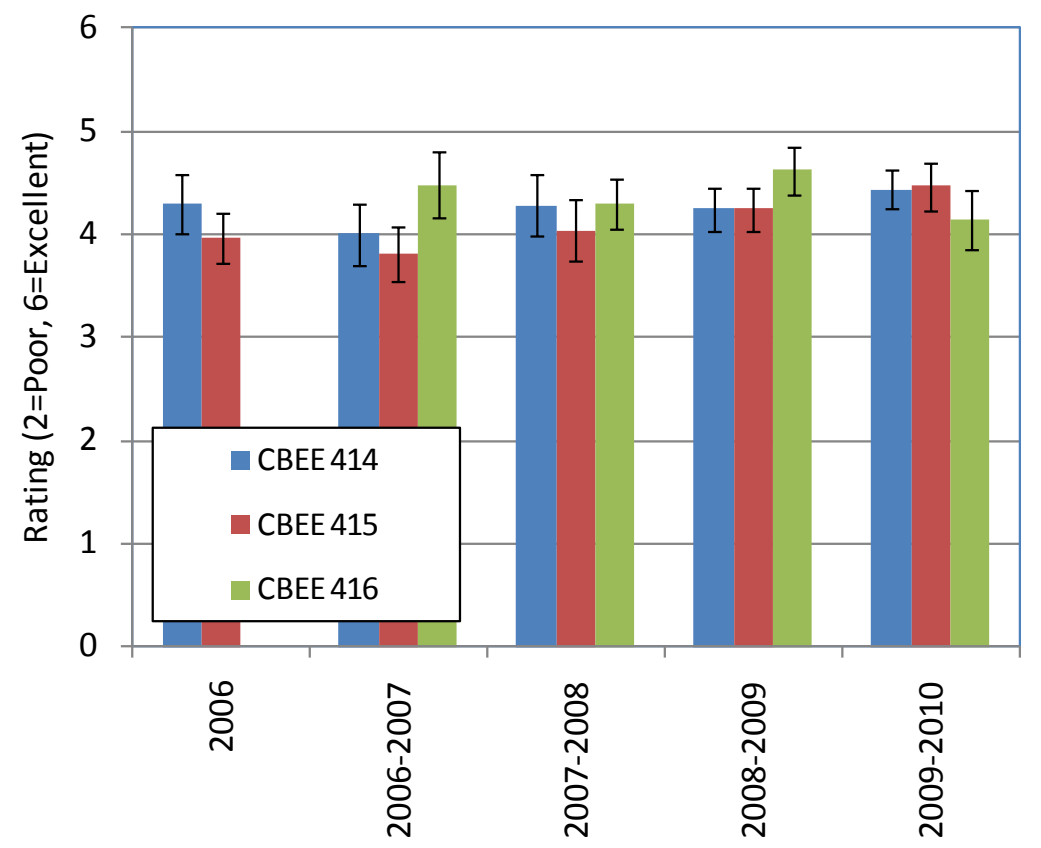

Figure 10: Student course evaluation responses to "The course as a whole was...”. Data for all 3 courses are presented over 5 years with error bars representing the 90 percent confidence intervals. Significant differences are not observed, indicating that combining disciplines, evolving curriculum, and doubled enrollment growth have not affected student perceptions of the courses.

\section{Conclusions and Plans for the Future}

The program described above represents significant growth and adaptation to change for the CBEE senior laboratory curriculum at Oregon State University. The structure has been put in place to deliver value to students in three different academic programs at a time of high enrollment growth. The course evaluation data indicate that this has not come at the expense of student perceptions of the course sequence. The challenge will continue, however, as enrollment will continue to grow in the senior laboratory sequence as shown by the projections in Figure 11 based on lower division course enrollments. Our response will be to hire an additional instructor and begin partitioning the class and laboratory activities more cleanly to maintain instruction quality and, more importantly, the quantity and rapidity of feedback to students. 


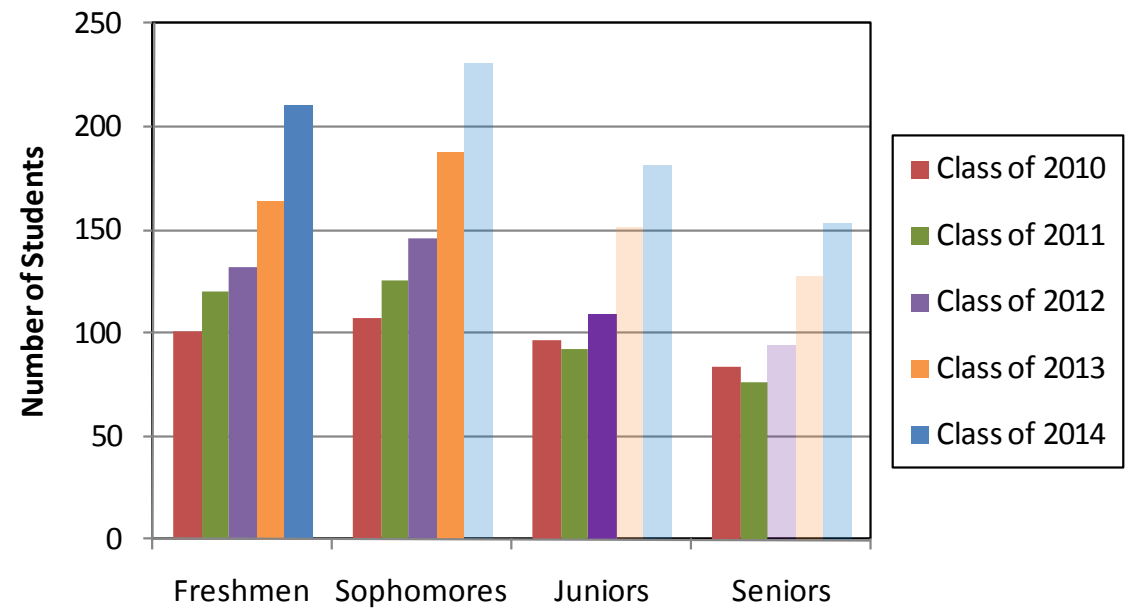

Figure 11: Enrollment trends for CBEE across four years. Transparent columns indicate enrollment projections based on current enrollments and historical attrition rates. Not shown is the $110 \%$ growth in senior enrollment across years 2006 to 2010. Freshman to sophomore growth is due to transfer students.

\section{Acknowledgements}

The authors acknowledge Peter and Rosalie Johnson for establishing the Linus Pauling Chair to honor Oregon State University's most famous graduate. Mr. Johnson is a 1955 OSU chemical engineering graduate and founder of Tekmax, Inc., a company which revolutionized battery manufacturing equipment. Dr. Christine Kelly was instrumental in design of the senior lab sequence and several unit operations lab experiments and provides instruction for the virtual bioreactor. Dr. David Hackleman developed CBEE 416 and served as the Linus Pauling Engineer for 5 years. The authors are indebted to numerous practicing engineers for sharing their time and experiences with students. Finally, several faculty members sponsor senior projects, committing resources and knowledge.

\section{References}

1. Feisel, L. D. and A. J. Rosa. (2005). The role of the laboratory in undergraduate engineering education. J. Eng. Educ., 94, 121-130.

2. Wankat, P.C. and F.S. Oreovicz. (1993). Teaching engineering. New York: McGraw-Hill.

3. ABET Website, http://www.abet.org/, retrieved Jan. 2011.

4. Dutson, A., R. Todd, S. Magleby, and C. Sorensen. 1997. A Review of Literature on Teaching Engineering Design Through Project-Oriented Capstone Courses. J. Eng. Ed., 86, 17-28.

5. Ma, J., and J.V. Nickerson. (2006). Hands-on, simulated, and remote laboratories: A comparative literature review. ACM Computing Surveys, 38, 1-24.

7. Todd, R. H., S. P. Magleby, C. D. Sorensen, B. R. Swan and D. K Anthony. (1995). A Survey of Capstone Engineering Courses in North America. J. Eng. Edu., 84, 165-174.

8. Smith, K.A. (2000). Strategies for Developing Engineering Student's Teamwork and Project Management Skills. Proceedings of the 2000 ASEE Annual Conference \& Exposition.

9. Porter, J. R., Morgan, J. A. and B. Zoghi. (2002). Integrating Project Management into the Capstone Senior Design Course. Proceedings of the 2002 ASEE Annual Conference \& Exposition 
10. Froyd J. A. Watt, and J.M. Williams. (2002). Writing to Design/Designing to Write: Using the Correlation between Communication and Engineering to Improve Student Reflection. Proceedings of the 2002 ASEE Annual Conference \& Exposition.

11.http://osufoundation.org/howtogive/namingopportunities/endowedpositions/thelinuspaulingchairinchemicalengin eering/index.php, retrieved Mar. 10, 2011.

12. Koretsky, M.D., D. Amatore, C. Barnes, and S. Kimura, (2008). Enhancement of student learning in experimental design using a virtual laboratory. IEEE Transactions on Education, 51, 76-85.

13. Koretsky, M.D., S. Kimura, C. Barnes D.M. Graham, and D. Amatore. (2006). Experiential Learning of Design of Experiments Using a Virtual CVD Reactor. Proceedings of the 2006 American Society for Engineering Education Annual Conference \& Exposition.

14. Kelly, C., E. Gummer, P. Harding and M.D. Koretsky, (2008). Teaching Experimental Design using Virtual Laboratories: Development, Implementation and Assessment of the Virtual Bioreactor Laboratory. Proceedings of the 2008 American Society for Engineering Education Annual Conference \& Exposition.

15. Koretsky, M, C. Kelly, P. Harding, and E. Gummer, (2009). Comparison of Student Perceptions of Virtual and Physical Laboratories. Proceedings of the 2009 American Society for Engineering Education Annual Conference \& Exposition.

16. http://wic.oregonstate.edu/, retrieved Mar. 9, 2011. 